
\title{
28 Research Square \\ Risk of multi-drug resistant Campylobacter spp. and residual antimicrobials at poultry farms and live bird markets in Bangladesh
}

Sucharit Basu Neogi

Osaka Prefecture University

Md. Mehedul Islam

Bangladesh Agricultural University

SK Shaheenur Islam

Department of Livestock Services

A.H.M. Taslima Akhter

Food and Agriculture Organization of the United Nations

Md. Mahmudul Hasan Sikder

Bangladesh Agricultural University

Shinji Yamasaki

Osaka Prefecture University

S. M. Lutful Kabir ( $\square$ lkabir79@bau.edu.bd)

Bangladesh Agricultural University https://orcid.org/0000-0003-3684-3387

Research article

Keywords: ,

Posted Date: December 6th, 2019

DOI: https://doi.org/10.21203/rs.2.13481/v3

License: (c) (i) This work is licensed under a Creative Commons Attribution 4.0 International License.

Read Full License

Version of Record: A version of this preprint was published at BMC Infectious Diseases on April 15th, 2020. See the published version at https://doi.org/10.1186/s12879-020-05006-6. 


\section{Abstract}

Background: Understanding potential risks of multi-drug resistant (MDR) pathogens from the booming poultry sector is a crucial public health concern. Campylobacter spp. are among the most important zoonotic pathogens associated with MDR infections in poultry and human. This study systematically examined potential risks and associated socio-environmental factors of MDR Campylobacter spp. in poultry farms and live bird markets (LBMs) of Bangladesh. Methods: Microbial culture and PCR-based methods were applied to examine the occurrence and MDR patterns of Campylobacter spp. at hatcheries $(n=33)$, broiler farms $(n=122)$ and LBMs $(n=69)$. Antimicrobial residues in broiler meat and liver samples $(n=50)$ were detected by advanced chromatographic techniques. A questionnaire based crosssectional survey was conducted on socio-environmental factors. Results: In poultry farms, Campylobacter spp. was primarily found in broiler cloacal swab (21/49, 43\%), followed by drinking water $(8 / 24,33 \%)$, and meat $(8 / 28,29 \%)$ samples of broilers. Remarkably, in live bird markets, Campylobacter spp. was detected in higher prevalence in broiler meat $(14 / 26,54 \%)$, which could have an association with bacterial contamination in drinking water $(11 / 21,52 \%)$ and floor $(9 / 21,43 \%)$. Representative isolates $(n=71)$ were differentiated into two species: Campylobacter jejuni (66\%) and Campylobacter coli (34\%). Majority of C. jejuni $(33 / 47,70 \%)$ and C. coli $(14 / 24,58 \%)$ strains were observed to be MDR, showing resistance to amoxycilin, tetracycline and erythromycin, and additionally ciprofloxacin, norfloxacin, streptomycin, and azithromycin. Residual antimicrobials, including oxytetracycline, ciprofloxacin and enrofloxacin, were detected in majority of broiler liver (79\%) and meat (62\%) samples. Alarmingly, $33 \%$ and $19 \%$ of the liver and meat samples, respectively, contained residual antimicrobial concentration above acceptable limit. Inadequate personal and environmental hygiene, unscrupulously use of antimicrobials, improper waste disposal, and lack of health surveillance and quarantine facilities of diseased birds were distinguishable risk factors, with local diversity and compound influences on MDR pathogens. Conclusion: Potential contamination sources and anthropogenic risk factors associated with the alarming occurrence of MDR Campylobacter, noted in this study, would aid in developing interventions to minimize the increasing risks of poultry-associated MDR pathogens under 'One Health' banner that includes poultry, human and environment perspectives.

\section{Background}

Campylobacterspp. are among the leading causes of food-borne infections causing human gastroenteritis [1] in both developing and developed countries. Approximately 9.0 and 1.0 million annual cases of campylobacteriosis, mostly due to Campylobacter jejuni, have been reported in the European Union (EU) and United States, respectively [2, 3]. Children under 5 years and adolescents aged 15 to 25 years are more susceptible to campylobacteriosis, while immune-compromised people can develop prolonged and severe illness by Campylobacterspp. [4]. The common clinical symptoms of campylobacteriosis include fever, abdominal pain, and diarrhea, which are mostly self-limiting, but antimicrobials, particularly, erythromycin, tetracycline, and fluoroquinolones, are often used.

Campylobacter has been associated with at least $11-21 \%$ of diarrhea episodes in children from low 
income countries [5]. Campylobacterspp., including C. jejuni, are also recognized as antecedent cause of particular post-infectious neuropathies, namely, Guillain-Barré syndrome, and autoimmune diseases, including Miller Fisher syndrome, reactive arthritis and irritable bowel syndrome [6]. Gastroenteritis by Campylobacter infections showed an increasing trend since the last decade [3]. The cytolethal distending toxin (CDT), consisting of CdtA, CdtB, and CdtC subunits, of Campylobacterspp. is one of the major virulence factors which contributes to cell cycle arrest, leading to the apoptosis or necrosis of immune cells, and epithelial cells in the intestine [7].

The gastrointestinal tract of poultry and other birds constitute the primary reservoir of Campylobacter spp., and the majority (50 to $80 \%$ ) cases of campylobacteriosis in humans is attributable to consumption of poultry products [8]. C. jejuni and C. coli are the predominant campylobacters in poultry, regardless of whether the animals are sick or healthy. Human populations, especially, toddlers and children, often become infected with Campylobacterspp. through contaminated food, and by means of water- and airborne infection from various environmental sources, particularly, as a consequence of poor sanitation and hygiene practice in poultry production and supply chain in developing countries including Bangladesh $[5,9]$.

Antimicrobial resistance (AMR) has become a serious problem worldwide. Approximately 700,000 deaths have been estimated due to AMR in 2013 throughout the world, whereas, according to a prediction, ca. $10,000,000$ people may die in 2050 if no action is taken [10]. Unwise antimicrobial use in poultry farms induces selective pressure on zoonotic pathogens, including campylobacters, to develop resistant strains and has been increasingly recognized as an important public health issue, particularly in developing countries like Bangladesh.

In Bangladesh, there have been an increasing Government efforts through registered veterinarians to promote a prudent use of antimicrobial agents and only for therapeutic purposes [11], yet these drugs are often applied indiscriminately in the poultry farms. Due to lack of hygienic practices and knowledge to manage rampant pollutions in different socio-environmental conditions, majority of the population in Bangladesh is highly prone to health disasters associated with MDR infections from the emergent poultry sector. Since a few studies have observed the occurrence and antibiotic susceptibility patterns of Campylobacterspp. in poultry farms, detection of antimicrobial residues, together with socioenvironmental risks prevailing in poultry farming and LBMs in Bangladesh have not been adequately explored $[12,13]$.

Being among the most heavily populated regions, there is always a high demand of broiler meat and eggs production in Bangladesh. Inevitably, the poultry industries in this country are inclined to adopt intensive farming methods, including unjudicial use of antimicrobials. Considering the enormous threats of multi-drug resistant Campylobacterspp. and antimicrobial residues from poultry industries in the near future, this study aimed to detect Campylobacter spp., their antimicrobial resistance patterns, and the extent of antimicrobial residues in potential sources of poultry farms and LBMs, and explored the associated anthropogenic risk factors. The purpose of this study was to empirically understand the risks 
of MDR infections by campylobacters, occurrence of antimicrobial residues and inducing socioenvironmental factors along the poultry production and supply chain in Bangladesh.

\section{Methods}

\section{Sampling sites, collection and processing of samples}

In three categories (farm, hatchery and LBM) a total of 224 samples were collected during October, 2015 to May, 2016 from 9 broiler farms, 7 hatcheries and 4 LBMs in three sub-districts (Gazipur sadar, Sreepur and Tangail sadar) of two poultry-dense districts (Gazipur and Tangail) of Bangladesh. The selection of the broiler farms was based on an inclusion criterion of a minimum flock size of 2000 , while the hatcheries and LBMs located beyond $10 \mathrm{~km}^{2}$ of the selected broiler farms were excluded. In each subdistrict 3 broiler farms, and at least 2 hatcheries and one LBM were selected, keeping a minimum distance of $2 \mathrm{~km}$ for multiple sites of each category. Farm samples included broiler meats $(B M-F, n=28)$, cloacal swabs $(C S, n=49)$, feed $(F, n=21)$, and drinking water $(W, n=24)$. Samples from hatcheries included chick meconium (CM, $n=33)$. LBM samples included broiler meats (BM-M, $n=27)$, drinking water $(W, n=21)$, and floor swabs (FS, $n=21)$. Moreover, a total of 50 samples, including broiler meat ( $n$ $=26$, each representing a composite of thigh, breast and drumstick) and liver $(n=24)$ were sampled from LBMs for screening of antimicrobial residues. To minimize sampling bias, three sub-samples $(100 \mathrm{~g})$ of each sample were randomly collected and pooled together following aseptic measures. After collection, the samples were kept in sterile plastic containers, transported in an insulated foam box with cold chain (temperature, $4-6^{\circ} \mathrm{C}$ ) and processed within $6 \mathrm{~h}$ of collection. A portion $(10 \mathrm{~g})$ of each sample was mixed with $10 \mathrm{~mL}$ phosphate buffer saline (pH 7.4) and homogenized with a tissue grinder (Seward Medical Ltd, London, UK).

\section{Culture based detection of Campylobacterspp.}

Aliquots (100 $\mu \mathrm{l}$ each) of the homogenized samples were added onto membrane filter (mixed cellulose ester type, $0.45 \mu \mathrm{m}$ pore size, $47 \mathrm{~mm}$ diameter; Biotech, Germany), which was overlaid on blood agar medium (blood base agar no. 2; Oxoid, UK), supplemented with $5 \%$ defibrinated sheep blood, and cultured under microaerophilic conditions at $37^{\circ} \mathrm{C}$ for 48 hours, according to Shiramaru et al. (2012) [14]. Presumptive Campylobacter isolates were subjected to species-specific morphological and biochemical assays, including Gram's staining, motility test, catalase, oxidase, and hippurate hydrolysis, according to standard procedures [6].

\section{PCR-based confirmation of the species identity}

DNA template of each isolate of Campylobacter spp. was prepared by boiling method described by Hoshino et al. (1998) [15]. In brief, a pure bacterial colony grown on blood based agar was mixed gently in $250 \mu \mathrm{L}$ distilled water and subjected to boiling, followed by immediate cooling on ice, for 10 minutes each. The tubes were then centrifuged at $10,000 \mathrm{X} g$ for 10 minutes and the supernatant was collected as DNA template for polymerase chain reaction (PCR). Initially, PCR screening targeting 16S rRNA gene was 
performed according to Samosornsuk et al. (2007) [16] to confirm whether the strains belonged to the genus Campylobacter. Afterwards, $c d t C$ gene based multiplex PCR was done for species-specific ( $C$. jejuni, $C$. coli and $C$. fetus) identification following methods described by Asakura et al. (2008) [17]. DNA templates of $C$. jejuni ATCC33560, C. coli ATCC33559 and C. fetus ATCC27374 strains were used as positive controls, and that of Escherichia coli ATCC 25922, grown in Luria-Bertani broth (Difco, MI, USA) at $37^{\circ} \mathrm{C}$ overnight, was used as a negative control. Details of all primers and corresponding PCR amplicon sizes are shown in Suppl. Table 1. PCR products were subjected to gel electrophoresis (1.5\% agarose, Invitrogen, USA) and after staining with ethidium bromide $\left(0.5 \mu \mathrm{g} \mathrm{ml}^{-1}\right)$ and destaining with distilled water, each for 10 minutes, gel images were captured using a UV transilluminator (Biometra, Germany).

\section{Determination of antimicrobial resistance}

All Campylobacter strains were tested for their resistance pattern by standard disk diffusion method. Eight commonly used antimicrobials with standard doses $(\mu \mathrm{g})$ were examined: amoxycillin (AMX, $30 \mu \mathrm{g})$, azithromycin (AZM, 30), ciprofloxacin (CIP, $5 \mu \mathrm{g})$, erythromycin (ER, $30 \mu \mathrm{g})$, gentamicin (GM, $10 \mu \mathrm{g})$, tetracycline (TET, $30 \mu \mathrm{g})$, streptomycin (STR, $10 \mu \mathrm{g}$ ) and norfloxacin (NOR, $10 \mu \mathrm{g})$. In brief, freshly grown broth culture (equivalent to $0.5 \mathrm{McF}$ arland turbidity) of each strain was uniformly inoculated, using sterile cotton swab, over the entire surface of Muller Hinton agar (Oxoid, UK), supplemented with $5 \%$ defibrinated sheep blood. Afterwards, 3-4 antimicrobial discs were placed in each agar plate and incubated at $37^{\circ} \mathrm{C}$ for $48 \mathrm{~h}$ under microaerobic conditions $\left(5 \% \mathrm{O}_{2}, 10 \% \mathrm{CO}_{2}\right.$ and $\left.85 \% \mathrm{~N}_{2}\right)$. The zones of growth inhibition were compared with the zone size interpretative standards as described by the Clinical and Laboratory Standard Institute (2007) [18] and thereby interpreted as susceptible (S), intermediate resistant (I) or resistant (R) to the antimicrobials. E. coli strain ATCC 25922 was used as a quality control organism. All data were confirmed by conducting at least two replicates of the disc diffusion experiments.

\section{Detection of antimicrobial residues}

A total of 50 samples, including broiler meat $(n=26)$ and liver $(n=24)$ were tested for the presence of oxytetracycline, ciprofloxacin and enrofloxacin residues. Solid phase extraction of the samples was performed according to Popelka et al. (2005) [19]. A portion (4 gm) of grinded meat or liver tissues was homogenized in $10 \mathrm{ml}$ phosphate buffer $(\mathrm{pH} 6.5)$, and treated with $2 \mathrm{~mL}$ trichloroacetic acid $(30 \%, \mathrm{v} / \mathrm{v})$ to fractionate the proteins, followed by centrifugation at $7000 \mathrm{X} \mathrm{g}$, and sonication in an ultrasonic bath, 15 min each. The supernatant (ca. $2 \mathrm{ml})$ was treated with formaldehyde $(100 \mu \mathrm{L})$ at $100^{\circ} \mathrm{C}$ for $45 \mathrm{~min}$, transferred to a new tube and mixed with equal amount of diethyl ether for 10 minutes at $25^{\circ} \mathrm{C}$, and the oily top layer was discarded. Extraction with diethyl ether was repeated twice. Afterwards, the extracts were filtered $(0.45 \mu \mathrm{m})$, dried by evaporation and reconstituted with $2 \mathrm{~mL}$ mixture of $99 \%$ methanol and acetone $(1: 1)$ to obtain the final extract, which was stored at $4^{\circ} \mathrm{C}$.

Standard solutions of residues of three antimicrobial agents, namely, oxytetracycline, ciprofloxacin and enrofloxacin, each $>98 \%$ purity, were prepared by dissolving $1.0 \mathrm{~g}$ powder of each in $5 \mathrm{~mL}$ methanol (99\%) and kept in the dark at $4^{\circ} \mathrm{C}$ until analysis by thin layer chromatography (TLC) within a week following 
standard procedures [19]. Briefly, TLC silica plates of $0.25 \mathrm{~mm}$ thickness (Merck, Germany) were activated at $120^{\circ} \mathrm{C}$ for $2 \mathrm{hrs}$ before inoculating $50 \mu$ of sample extract or standard solution of antimicrobial residues. Acetone-methanol (1:1) was used as mobile phase solvent and chromatographs were observed at $256 \mathrm{~nm}$. Each of the samples was analyzed in triplicate. An internal standard and a blank was included after every five samples during analysis by both methods.

Quantification of residual antimicrobials were done by ultra-high performance liquid chromatography (UHPLC) for the meat and liver samples, which showed positive by TLC, following procedures described

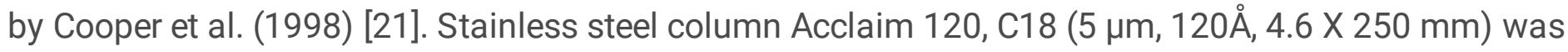
used for chromatography (Dionex ultimate 3000 UHPLC). Phosphate buffer solution was prepared by adding di-sodium hydrogen phosphate to $0.2 \mathrm{M}$ potassium di-hydrogen phosphate solution until pH 5.0. HPLC mobile phase constituted of distilled water and acetonitrile $(85: 15, \mathrm{v} / \mathrm{v})$ for oxytetracycline, and $0.01 \mathrm{M}$ phosphate buffer and acetonitrile $(80: 20, \mathrm{v} / \mathrm{v})$ for others. Acetonitrile was HPLC grade (Panreac, Italy) and other reagents were of p.a. grade (Merk, Germany). A portion $(25 \mu \mathrm{l})$ of each sample was injected into chromatographic column, equilibrated with mobile phase, and run at $0.8 \mathrm{ml} \mathrm{min}^{-1}$ until the mobile phase ascended $7 \mathrm{~cm}$. Afterwards, the column was air dried and visualized under UV light $(\lambda=254$ $\mathrm{nm}$ and $366 \mathrm{~nm}$ ). Standard controls ( 2 to $200 \mathrm{\mu g} \mathrm{ml}^{-1}$ ) were prepared by serially (2-fold) diluting the stock solution of each antimicrobial. Six replicates of each concentration were assayed to standardize the regression equation (coefficient value $>0.99$ ). Identification was done by comparing $\mathrm{Rf}$ values of antibiotic standards, i.e., $0.35,0.80$, and 0.97 for oxytetracycline, ciprofloxacine, and enrofloxacin, respectively. Peak area was used for antimicrobial quantification by regression analysis, $Y=a X+b$, where $\mathrm{Y}=$ component area or height, $\mathrm{a}=$ slope and $\mathrm{b}=$ intercept of the regression line, and $\mathrm{X}=$ estimated amount of antimicrobial. Extraction recovery was evaluated with comparison of peak areas for standard antimicrobial solution to that of the TLC-negative broiler tissue homogenates, spiked with the same standard solution.

\section{Data collection on health safety and hygiene practices}

A total of 14 broiler farms, including the 9 sampled farms and additional 5 farms in the same geographical locations were enrolled for survey using semi-structured interviews through participatory methods to understand poultry husbandry associated risks, personal and environmental hygiene, and vulnerabilities to campylobacter infections, antimicrobial usages, and occupational safety. Each semistructured interview was conducted involving at least a couple of representatives from each of the selected farms $(n=14)$ and responses were recorded in hardcopies. Two teams (A and B), each comprising three experienced veterinarians from the Bangladesh Agricultural University, conducted the interviews at two phases upon prior individual written consent of the farm managers or farmer owner. Team A collected data from half of the selected farms $(n=7)$ in the first phase, which were verified by Team $B$ in the second phase, and vice versa for the rest farms $(n=7)$. A total of 56 semi-structured interviews, including two from each farm at each of the two phases (3-month interval), were accomplished. 


\section{Data management and Statistical analyses}

Data were recorded into Microsoft Excel 10 (Microsoft Corporation, Redmond, WA, USA) spreadsheet from the hard copies and statistically analysed using 'Xact' (ver. 7.21d, SciLab GmbH, St. Yrieix, France) and Statistica (ver. 10.0, StatSoft Inc., USA). Fisher's exact test was performed to check significant difference or association $(\mathrm{p}<0.05)$ between the prevalence of Campylobacter species and any individual geo-socio-anthropogenic variables (study sites, and sample sources and types). Antimicrobial susceptibility profile of the bacterial isolates was compared as histograms. Descriptive comparison of resistant patterns of Campylobacter with respect to diversity in sources and/or anthropogenic factors was performed using mean/ median and standard deviation, and also in the form of the box plots. Differences in the patterns and/or occurrence of antibiotic resistance in Campylobacterspp. (C. coli and $C$. jejuni) were calculated by the Paired Sample T-test. A ' $p$ ' value of $<0.05$ was considered significant.

\section{Results}

\section{Detection and occurrence of Campylobacterspp.}

Of the 224 samples, a total of 71 (32\%) were contaminated with Campylobacter spp. as determined by culture-based methods (Table 1). One presumptive Campylobacter species was isolated from each of the 71 positive samples. When subjected to genus-specific 16S rRNA PCR, all of them produced an expected amplicon size of $1530 \mathrm{bp}$, confirming their identity as Campylobacterspp. Approximately one-third (30\%, 37 of 122) of the farm samples were observed to be contaminated with Campylobacter spp., with highest occurrence in cloacal swab (43\%), followed by drinking water (33\%) and broiler meat (29\%) (Table 1). However, all of the chick meconium samples $(n=33)$ at hatcheries, and feed samples $(n=21)$ from the broiler farms were observed to be negative for Campylobacter spp. On the other hand, Campylobacter spp. was found in approximately half $(49 \%, 34$ of 69$)$ of the LBM samples, including drinking water (52\%), floor swab (43\%) and broiler meat (52\%). Spatial variation (sub-district wise) in the contamination rate was observed for all kinds of samples at both the farm and market sources, although statistical variation ( $p<0.1$, Fisher's exact test) was only discernible between the total samples of Gazipur and Tangail districts (Table 1). At the poultry farms, Campylobacter occurrence in cloacal swab and broiler meat samples had significant association ( $p=0.0074$, Fisher's exact test). The risk of Campylobacter infection at broiler farms could be related to drinking water contamination, as indicated by its highly significant association $(p=0.0093)$ with the bacterial prevalence in broiler samples, both meat and cloacal swab (Table 1). Notably, the contamination rate for overall samples was significantly higher $(\mathrm{p}=$ 0.0125) at the LBMs when compared to the broiler farms. In the market environment, the observed high occurrence of Campylobacter spp. in broiler meat samples was associated with the bacterial relative occurrence in drinking water $(p=0.0075)$ and floor swab $(p=0.0043)$ samples (Table 1$)$.

Multiplex PCR assay targeting the $c d t C$ gene differentiated the Campylobacter isolates into 47 C. jejuni and $24 \mathrm{C}$. coli, producing species-specific amplicon of $524 \mathrm{bp}$ and $313 \mathrm{bp}$, respectively (Suppl. Fig. 1). In both LBMs and farm environment, Campylobacter isolates were dominated by $C$. jejuni. Of the 37 isolates 
from the farm samples, $24(65 \%)$ and $13(35 \%)$ were identified as $C$. jejuni and $C$. coli, respectively. Similarly, out of 34 campylobacters isolated from the market samples, $23(68 \%)$ and $11(32 \%)$ were identified as $C$. jejuni and $C$. coli, respectively.

\section{Antimicrobial resistance patterns in Campylobacter strains}

The zone of growth inhibition for each strain of $C$. jejuni and $C$. coli was compared with the interpretative standard [17] for each of the selected antimicrobials (Fig. 1, Suppl. Table 2). Of the 47 C. jejuni isolates, majority showed resistant to amoxycilin $(n=30,64 \%)$, erythromycin $(n=29,62 \%)$ and tetracycline $(n=$ $24,51 \%)$, followed by ciprofloxacin $(n=17,36 \%)$, norfloxacin $(n=12,26 \%)$, streptomycin $(n=12,26 \%)$, azithromycin $(n=7,15 \%)$ and gentamycin $(n=2,4 \%)$. Similarly, among the 24 C. coli strains higher resistance to amoxycilin ( $n=13,56 \%)$, erythromycin $(n=11,46 \%)$ and tetracycline $(n=10,42 \%)$, and comparatively lower resistance to other tested antimicrobials, including ciprofloxacin $(n=7,29 \%)$, norfloxacin $(n=8,33 \%)$, streptomycin $(n=6,25 \%)$, azithromycin $(n=4,17 \%)$ and gentamycin $(n=2,8 \%)$, were observed.

A considerable portion of the $C$. jejuni and $C$. coli strains showed intermediate resistance pattern to the tested antimicrobials, ranging from 9 to $28 \%$ and 8 to $33 \%$ strains of these two species, respectively (Fig. 1 A-B and Suppl. Table 2). A higher percentage of Campylobacter strains isolated from farm than market samples were observed to be fully resistant to most of the tested antimicrobials. However, occurrence of intermediate resistance to the antimicrobials were observed to be significantly higher $(p<0.01)$ in $C$. jejuni and $C$. coli strains, isolated from LBMs, when compared to those of the farm samples (Fig $1 \mathrm{C}-\mathrm{F}$ ).

Among the isolated strains $(\mathrm{n}=47)$ of $C$. jejuni, $10(21 \%)$ were resistant to two antimicrobial agents, while $11(23 \%)$ were resistant to three antimicrobial agents. Alarmingly, about $20 \%(n=9)$ strains of $C$. jejuni showed resistance against five or more antimicrobial agents, including amoxicillin, erythromycin, tetracycline, norfloxacin and azithromycin/gentamycin (Table 2). In case of $C$. coli strains $(n=24), 4$ $(16 \%)$ and $6(25 \%)$ showed resistance against two and three antimicrobial agents, respectively, while a few, i.e., 1 (4\%) and 3 (12\%), were resistant to four and five antimicrobial agents (Table 2). Overall, $C$. jejuni strains showed higher percentage $(n=33,70 \%)$ of resistance to at least three antimicrobial agents than that of $C$. coli strains $(n=14,58 \%)$.

\section{Occurrence of antimicrobial residues}

Detection of oxytetracycline, ciprofloxacin and enrofloxacin residues by TLC showed their presence in majority of the broiler samples, with higher contamination rate for liver tissues ( 19 of $24,79 \%$ ) than meat samples (16 of $26,62 \%)$. In both kinds of samples, comparatively higher occurrence of oxytetracycline (38 and 31\%, respectively) than ciprofloxacin (25 and 19\%) and enrofloxacin (17 and $12 \%$ ) was observed (Table 3).

UHLP-based quantification of antimicrobial residues in meat and liver samples showed the concentration of oxytetracycline, ciprofloxacin and enrofloxacin ranging from 10 to 155,25 to 135 , and 50 to $115 \mu \mathrm{gg}$ 
${ }^{1}$, respectively (Table 3 ). Considering the concentration range of these antimicrobials, a significant difference between liver and meat samples was not discernible. However, higher frequency (8 of 24, 33\%) of liver than meat ( 5 of $26,19 \%$ ) samples had antimicrobial residues (Table 3 ) above the recommended level $\left(100 \mu \mathrm{g} \mathrm{kg}^{-1}\right)$ for food safety [22].

\section{Environmental health and hygiene practices}

Data obtained from semi-structured interviews of the poultry handlers from the selected 14 broiler farms are summarized in Fig. 2. Among the anthropogenic factors associated with the occurrence of MDR Campylobacter, extensive use of antimicrobial agents was captured in all except one of the farms (Fig. $2 A)$. Majority of the farms ( $71 \%)$ usually discarded the poultry-generated waste into agriculture lands while about one-third (30\%) of the farms also discarded poultry faeces into aquaculture ponds as fish feed. Quarantine or isolation of sick birds was practiced in $57 \%$ of the farms. Periodic health check-up by the veterinary authorities and observation of gastroenteritis were reported for nearly half (45\%) of the surveyed farms. Use of disinfectants or cleaning solution to prevent infection from common pathogens and spread of campylobacteriosis, and other gastroenteritis remedies was practiced in approximately one-third $(36 \%)$ of the farms. On the other hand, regular cleaning of the pots used for feeding and watering, and washing of the floors (of the cages) was done only in small proportion (21 and $14 \%$, respectively) of the farms. Pre-handling hand washing to minimize cross-contamination between broilers was practiced in only 8 out of $14(57 \%)$ farms. However, hand washing interventions, post-handling and before eating, as part of occupational and personal safety, were practiced by only a minor faction (29 and $21 \%$, respectively) of the farmers. All of the representative farmers and poultry-handlers regularly consumed broiler meat and liver reared in their farms. Gastroenteritis among the poultry handlers were reported in majority of the farms, including 5 of 6 farms reporting campylobacteriosis in broilers, which were associated with compound influences of several anthropogenic factors (Fig. 2B). Comparison of symptomatic and asymptomatic infections in individual farms indicated that diverse combinations of multiple risk factors, concerning hygiene (e.g., hand washing, and proper cleaning), poultry rearing practices, waste disposal and health management, were synergistic socio-environmental drivers of the MDR Campylobacter pathogens in poultry sector.

\section{Discussion}

Emergence of MDR bacteria from poultry farms is a major threat to public health, especially in low- and middle-income countries. The poultry industry is among the rapidly growing agro-based enterprises with an annual increasing rate of $20 \%$ per annum in Bangladesh [23]. Being the major reservoirs of Campylobacterspp., poultry and livestock are mainly responsible for the ongoing spread of campylobacteriosis throughout the world. Campylobacters, particularly, $C$. jejuni and $C$. coli have been recognized as the predominant zoonotic bacteria associated with gastrointestinal disorders in humans since the last decade $[3,24]$. Recent investigations have claimed a close association of gastroenteritis caused by these pathogens with the widespread occurrence of malnourished under- 5 children in developing countries including Bangladesh [5]. The present study provides a glimpse on the occurrence 
and potential risks of Campylobacter pathogens and antimicrobial residues at multiple sources of poultry production and supply chain in Bangladesh.

Studies in tropical regions have observed large differences in Campylobacter prevalence in poultry samples, e.g., 32 and $65 \%$ of broiler flocks in Vietnam and Ecuador $[25,26]$. Similarly, the variations in Campylobacter occurrence at farms and LBMs in this study may be attributed to the impacts of differential anthropogenic practices and environmental variations. Although not observed, contaminated chick meconium in hatcheries and also supplied feeds in broiler farms may be a potential source of poultry diseases [27]. Higher occurrence of Campylobacter in cloacal swabs is in accordance with the bacterial natural colonization of broiler intestines, considered as the primary source of contamination in poultry products and environment [28]. The predomination of $C$. jejuni over $C$. coli among the isolated strains from both the poultry farms and LBMs has been a common trend worldwide [29]. In comparison to broiler farms, the higher occurrence of Campylobacterspp. in meat samples of LBMs is probably linked to large-scale contamination of feed water and floor environment, facilitating widespread secondary transmission of this zoonotic pathogen. Even in developed countries, with good farming practices and health interventions, frequent contamination of poultry products by Campylobacterspp. at retail markets and slaughter houses is still a major cause of food-borne illness [31, 32].

Large-scale application of antimicrobials as human and veterinary medicine or prophylactic is imposing an immense challenge to public health. In the context of high population density $\left(>1,200 \mathrm{Km}^{2}\right)$ within a small country, the situation is very complex in Bangladesh. High occurrence of MDR strains of Campylobacter has been reported worldwide [31, 32]. Likewise, a large fraction of $C$. jejuni and $C$. coli populations in poultry samples in this study has been observed as resistant to commonly used antimicrobials, e.g., amoxycilin, erythromycin and tetracycline. Notably, some of these MDR strains, e.g., ca. $20 \%$ of $C$. jejuni strains, have also gained resistance to not only $\beta$-lactam but also aminoglycoside, quinolone and macrolide, which is in accordance with previous observations [12]. The patterns of resistance traits in Campylobacter spp. are usually variable, spatio-temporally and also with geo-socioclimatic variations. This may explain the dissimilarity in major resistance patterns among Campylobacter strains reported in different studies. For example, in contrast to the results obtained in this study a low frequency of erythromycin resistant strains but high frequency of resistance to ciprofloxacin, nalidixic acid and tetracycline were reported for Campylobacter isolates in Brazil [33]. The higher frequency of resistant strains in $C$. jejunithan $C$. coli (Table 2) could be related to the overwhelming natural predominance of the former species. However, in comparison to $C$. jejuni, higher proportion of $C$. coli strains have been reported to be resistant to tetracycline and erythromycin in Europe and China, respectively [34,35]. On the other hand, relatively low prevalence of resistant Campylobacter strains in market samples than broilers farms (Fig. 1) can be attributable to natural decay of active component of antimicrobials, which are usually applied at the farm level. This inference is also supported by our observation of a significantly $(p<0.01)$ increased abundance of intermediate resistant strains in markets than poultry farms. 
The presence of antimicrobial residues, largely unexplored in poultry products, is thought to induce resistance among naturally occurring gut flora and potentially contribute to spreading of MDR strains, eventually health hazards, e.g., gastrointestinal and neurological disorders, hypersensitivity, and tissue damage in animal and human populations [36]. In Ho Chi Minh, Vietnam, the occurrence of ESBLproducing $E$. coli in $>50 \%$ of asymptomatic healthy human populations, presumably pre-exposed to residual antimicrobials, coincided with an increasing severity in food-borne diseases [36]. Interaction with antimicrobial chemicals, at sub-lethal concentration, may modulate the bacterial genetic mechanisms conferring MDR traits in Campylobacterstrains. Among the known genetic mechanisms of such antimicrobial resistance include the horizontal transfer of multiple resistant genes, often found tandemly located in large mobile elements (e.g., plasmids, Class I integron, conjugative transposon) in the bacterial genome and mutations in genes, including gyrA and gyrB of DNA gyrase and parC and parE of topoisomerase IV, regulating efflux pump systems and insertional modulation in $c m e B$ gene inactivating the $\mathrm{CmeABC}$ multidrug efflux pump [37]. The presence of residual content of antimicrobials in most of the tested poultry meat and liver samples in this study is similar to observations reported from another region in Bangladesh [13]. The higher occurrence of such contamination in liver tissue than meat samples (Table 3) is in accordance with their biological processing within poultry animal. In comparison to oxytetracycline, less frequently observed contamination of ciprofloxacin/ enrofloxacin may be related to their relative use in poultry farms. Considering food safety aspects [22], knowledge on the harmful impacts of antimicrobial residues above the acceptance level in broiler tissues, including liver, need to be translated among both the poultry producers and consumers.

Despite sanitation efforts and control measures, in a limited scale, outbreaks of zoonotic diseases are frequent in Bangladesh [38]. According to this study, the level of hygienic and bio-safety measures, e.g., regular hand washing, use of disinfectants, cleaning of the utensils, and washing of the floors and cages are very poor in poultry farms and markets. Therefore, people working in poultry farms and markets are at high risk of occupational health hazards caused by campylobacter infections. An estimated $20-30 \%$ of human campylobacteriosis cases have been attributed to imprudent handling, preparation and consumption of broiler meat [39]. Not only the farmers but also other stakeholders, namely, poultry handlers in the LBMs, storekeepers, restaurant owners and household members are responsible to maintain adequate environmental and food hygiene. This study clearly suggests an imperative need to reduce widespread occurrence of secondary contamination of Campylobacter in the LBM environment. Adopting optimal slaughtering process with reduced cross-contamination and proper washing with chlorinated water may effectively reduce bacterial loads on chicken carcasses [40]. Results of this study also point out the need of increased efforts in regular health monitoring and quarantine of sick chicken in poultry farms. People residing at a close proximity of poultry farms may also become vulnerable to MDR pathogens because of the large-scale use as fertilizer of poultry-generated waste, which should be properly treated before discarding to adjacent lands and aquatic ecosystems. However, Campylobacter infections in a vast majority of people, particularly in developing countries like Bangladesh often remain asymptomatic $[5,9]$. The diversity and compound influences of the potential risks of MDR Campylobacter (Fig. 2) need to be explored in more details with systematic and long-term observations of their spatio- 
temporal variations. However, this study did not include investigations measuring the minimum inhibitory compounds, understanding the genetic basis of antimicrobial resistance among the Campylobacter isolates, and comparing with antimicrobial resistance patterns among the human populations, which are prospective areas requiring further research. Since antimicrobial-induced genetic recombination and changing patterns in MDR traits in campylobacters poses a major challenge to health interventions, a combined application of multiple strategies, e.g., practicing good husbandry with prudent use of antimicrobials, maintaining adequate hygiene and sanitation, and introducing vaccination, probiotics, prebiotics, antimicrobial peptides, and herbal extracts, may be more effective to promote the sustainable growth of poultry sector [41, 42]. Developing management guidelines to combat zoonotic diseases requires systematic risk assessment along with the dynamics and diversity of MDR pathogens, including campylobacters, which are often challenging due to disproportionate vulnerabilities but crucial to participatory management. In this regard, the variety of sources, contamination level, and differential risks of MDR pathogens in poultry farms and LBMs, and inducing socio-environmental factors identified in this study will facilitate to adopting appropriate interventions to tackle health hazards from campylobacteriosis and other zoonotic diseases.

\section{Conclusion}

The observed high contamination of MDR $C$. jejuni and $C$. coli strains in broiler samples and diverse environmental sources at poultry farms, and their magnified occurrence at LBMs, is obviously related to the coinciding poor status of hygiene, bio-safety, and health management measures, reflecting an alarming situation for food safety in Bangladesh. Moreover, the presence of residual antimicrobials in majority of the broiler liver and meat samples, which may also stimulate MDR occurrence, is an emerging hazard to human and animal health. The systematic approaches followed in this study need to be integrated in future health programs correlating the occurrences of MDR Campylobacter in poultry and antimicrobial resistance among human populations, which would provide more insights into the extent of associated socio-environmental hazards. Based on the observed potential risks of MDR Campylobacter, it is recommended that not only the farm managers but also more assertively the poultry handlers at markets should be included in behavioural change motivational training programs to adopt preventable measures, including strict maintenance of personal and environmental hygiene, regular monitoring of poultry health and prudent use of antimicrobials. Participatory and holistic surveillance on the transmission dynamics of zoonotic pathogens and adoptable intervention strategies, following 'One Health' approaches, need to be promoted through multidisciplinary collaborations; otherwise, the impacts of poultry-originated MDR bacteria and residual antimicrobials to the food chain would bring appalling health disasters in the near future.

\section{List Of Abbreviations}

AMR: Antimicrobial resistance

BM-M: Broiler meat at LBMs 
BM-F: Broiler meat at farms

CDT: Cytolethal distending toxin

CS: Cloacal swab

LBM: Live Bird Market

F: Feed

FS: Floor swab

MDR: Multi-drug resistant

W: Drinking water

TLC: Thin-layer chromatography

UHPLC: Ultra-high performance liquid chromatography

\section{Declarations}

\section{Ethics approval and consent to participate}

Semi-structure interviews of representative informants were performed upon their prior consent. Letter of approval to conduct the study was received from the Ministry of Fisheries and Livestock, Bangladesh.

\section{Consent for publication}

Not applicable.

\section{Availability of data and materials}

The datasets generated and analysed during this study are available from the corresponding author on reasonable request. All data generated or analysed during this study are included in this published article [and its supplementary information files]. All the data generated in this study do not in any way allow poultry farms and markets, respondents, or study communities to be identified. Confidentiality of data is maintained anonymously.

\section{Competing interests}

The authors declare that they have no competing interests.

\section{Funding}


This study was supported by the Food Safety Program, FAO-UN, Bangladesh in partnership with Ministry of Fisheries and Livestock, Bangladesh under the project entitled "Improving Food Safety in Bangladesh (Grant no. GCP/BGD/047/NET)", co-financed by the Government of the Kingdom of the Netherlands.

\section{Authors' Contributions}

SBN designed the study, analyzed data and prepared the draft manuscript. MMI acquired the field data and performed microbiological analysis. SMLK, as the principal investigator of the research project, supervised the study, and finalized the manuscript. SY, advised and supervised the analysis. SSI and AHMTA facilitated field- and laboratory-based examinations and contributed in data analysis. All authors read and approved the final manuscript.

\section{Acknowledgments}

The authors appreciate the kind facilitation and valuable suggestions from Technical Expert, Food Safety Program of Food and Agriculture Organization of United Nations (FAO-UN), Bangladesh. The microbiological surveillance was part of the MS thesis of MMI, Department of Microbiology and Hygiene, Bangladesh Agricultural University.

\section{Author information}

\section{Affiliations}

Graduate School of Life and Environmental Sciences, Osaka Prefecture University, Osaka, Japan

Sucharit Basu Neogi and Shinji Yamasaki

Department of Microbiology and Hygiene, Bangladesh Agricultural University, Mymensingh-2202, Bangladesh

Md. Mehedul Islam and S. M. Lutful Kabir

Department of Pharmacology, Bangladesh Agricultural University, Mymensingh-2202, Bangladesh

Md. Mahmudul Hasan Sikder

Epidemiology Unit, Department of Livestock Services, Krishi Khamar Sarak, Farmgate, Dhaka-1215, Bangladesh

SK Shaheenur Islam

FAO-Food Safety Program (FSP), Institute of Public Health, Mohakhali, Dhaka-1215, Bangladesh

A.H.M. Taslima Akhter 


\section{Corresponding author}

Correspondence to S.M. Lutful Kabir

\section{References}

1. Keener KM, Bashor MP, Curtis PA, et al. Comprehensive review of Campylobacter and poultry processing. Compr Rev Food Sci. Food S 2004; 3(2): 105-116.

2. Havelaar AH, Ivarsson S, Lofdahl M, et al. Estimating the true incidence of campylobacteriosis and salmonellosis in the European Union, 2009. Epidemiol Infect. 2013; 141(2): 293-302. https://doi.org/10.1017/S0950268812000568.

3. Scallan E, Hoekstra RM, Angulo FJ et al. Foodborne illness acquired in the United States - major pathogens. Emerg Infect Dis. 2011;17(1): 7. https://dx.doi.org/10.3201/eid1701.p11101.

4. Friedman, $\mathrm{CR}$, Neimann J, Wegener HC, et al. Epidemiology of Campylobacter jejuni infections on the United States and other industrialized nations. Campylobacter. 2000; 121-138.

5. Platts-Mills JA, Kosek M. Update on the burden of Campylobacter in developing countries. Curr Opin Infect Dis. 2014; 27(5): 444. https://dx.doi.org/ 10.1097/QC0.0000000000000091.

6. Nachamkin I. Campylobacter and Arcobacter. Manual of Clinical Microbiology. American Society for Microbiology. Washington, DC. 2003; 902-914.

7. Yamasaki S, Asakura M, Tsukamoto T, et al. Cytolethal distending toxin (CDT): genetic diversity, structure and role in diarrheal disease. Toxin Rev. 2006; 25: 61-88. https://doi.org/10.1080/15569540500320938.

8. Skarp CPA, Hänninen ML, Rautelin H, et al. Campylobacteriosis: the role of poultry meat. Clin Microbiol Infect. 2016; 22(2): 103-109. https://doi.org/10.1016/j.cmi.2015.11.019.

9. Taniuchi M, Sobuz SU, Begum S, et al. Etiology of diarrhea in Bangladeshi infants in the first year of life analyzed using molecular methods. J Infect Dis. 2013; 208(11): 1794-1802. https://doi.org/10.1093/infdis/jit507.

10. O'neill J. Antimicrobial resistance: tackling a crisis for the health and wealth of nations. Rev Antimicrob Resist. 2014; 20:1-16.

11. Department of Livestock Services, Ministry of Fisheries and Livestock, Government of the Peoples' Republic of Bangladesh. Animal Feed Act. 2010; 1-9. http://www.dls.gov.bd/

12. Kabir SML, Sumon MH, Amin MM, et al. Isolation, identification and antimicrobial resistance patterns of Campylobacterspecies from broiler meat sold at KR Market of Bangladesh Agricultural University Campus, Mymensingh. J Agric Food Technol. 2014; 4:15-21.

13. Sattar S. Hassan MM. Islam SK, et al. Antibiotic residues in broiler and layer meat in Chittagong district of Bangladesh. Vet World. 2014; 7(9): 738-743. https://dx.doi.org/14202/vetworld.2014.738743. 
14. Shiramaru S, Masahiro A, Haruna I, et al. Cytolethal distending toxin gene-based multiplex PCR assay for detection of Campylobacter in stool specimens and comparison with culture method. J Vet Med Sci. 2012; 74(7): 857-862.

15. Hoshino K, Yamasaki S, Mukhopadhyay AK, et al. Development and evaluation of a multiplex PCR assay for rapid detection of toxigenic Vibrio cholerae 01 and 0139. FEMS Immunol Med Microbiol. 1998; 20(3): 201-207.

16. Samosornsuk W, Asakura M, Yoshida E, et al. Evaluation of a cytolethal distending toxin (cdt) genebased species-specific multiplex PCR assay for the identification of Campylobacter strains isolated from poultry in Thailand. Microbiol Immunol. 2007; 51(9): 909-917.

17. Asakura M, Samosornsuk W, Hinenoya A, et al. Development of a cytolethal distending toxin (cdt) gene-based species-specific multiplex PCR assay for the detection and identification of Campylobacter jejuni, Campylobacter coli and Campylobacter fetus. FEMS Immunol Med Microbiol. 2008; 52(2): 260-266.

18. Performance standards for antimicrobial susceptibility testing.17th Informational Supplement document M100-S17. 2007; 32-50. Clinical and Laboratory Standards Institute. Wayne, Pennsylvania.

19. Popelka P, Nagy J, Germuska R, et al. Comparison of various assays used for detection of betalactam antibiotics in poultry meat. Food Addit Contam. 2005; 22(6): 557-562. https://doi.org/10.1080/02652030500133768.

20. Thangadurai S, Shukla SK, Anjaneyulu Y, et al. Separation and detection of certain $\beta$-lactam and fluoroquinolone antibiotic drugs by thin layer chromatography. Anal Sci. 2002; 18(1): 97-100. https://doi.org/10.2116/analsci.18.97.

21. Coope AD, Stubbings GWF, Kelly M, et al. Improved method for the on-line metal chelate affinity chromatography-high-performance liquid chromatographic determination of tetracycline antibiotics in animal products. J Chromatogr A. 1998; 812(1-2): 321-326.

22. European Commission. Commission Regulation (EU) No. 37/2010 of 22 December 2009 on pharmacologically active substances and their classification regarding maximum residue limits in foodstuffs of animal origin. Official Journal of European Union. 2010; 15: 1-72.

23. Lonkar P, Harne SD, Kalorey DR, et al. Isolation, in vitro antibacterial activity, bacterial sensitivity and plasmid profile of Lactobacilli. Asian-Australas J Anim Sci. 2005; 18(9): 1336-1342. https://doi.org/10.5713/ajas.2005.13.

24. European Food Safety Authority. Scientific opinion on Campylobacter in broiler meat production: control options and performance objectives and/or targets at different stages of the food chain. EFSA J. 2011; 9: 2105. https://doi.org/10.2903/j.efsa.2011.2105.

25. Carrique-Mas JJ, Bryant JE, Cuong NV, et al. An epidemiological investigation of Campylobacter in pig and poultry farms in the Mekong delta of Vietnam. Epidemiol Infect. 2014; 142(7): 1425-1436.

26. Vinueza-Burgos $C$, Wautier M, Martiny D, et al. Prevalence, antimicrobial resistance and genetic diversity of Campylobacter coli and Campylobacter jejuni in Ecuadorian broilers at slaughter age. 
Poult Sci. 2017; 96(7): 2366-2374. https://doi.org/10.1371/journal.pone.0207567.

27. Mohanta MK, Islam MS, Saha AK, et al. Antibiogram profiles of bacterial isolates from poultry feeds and moribund hens in Rajshahi, Bangladesh. Imp J Interdiscip Res. 2016; 2(5): 41-46.

28. Romero-Barrios P, Hempen M, Messens W, et al. Quantitative microbiological risk assessment (QMRA) of food-borne zoonoses at the European level. Food Control. 2013; 29(2): 343-349. https://doi.org/10.1016/j.foodcont.2012.05.043.

29. Kramer JM, Frost JA, Bolton FJ, et al. Campylobacter contamination of raw meat and poultry at retail sale: identification of multiple types and comparison with isolates from human infection. J Food Prot. 2000; 63(12): 1654-1659. https://doi.org/10.4315/0362-028X-63.12.1654.

30. Reich F, Valero A, Schill F, et al. Characterisation of Campylobacter contamination in broilers and assessment of microbiological criteria for the pathogen in broiler slaughterhouses. Food Control. 2018; 87: 60-69. https://doi.org/10.1016/j.foodcont.2017.12.013.

31. Zhao S, Young SR, Tong E, et al. Antimicrobial resistance of Campylobacter isolates from retail meat in the United States between 2002 and 2007. Appl Environ Microbiol. 2010; 76(24): 7949-7956.

32. Han $X$, Zhu D, Lai $H$, et al. Prevalence, antimicrobial resistance profiling and genetic diversity of Campylobacter jejuni and Campylobacter coli isolated from broilers at slaughter in China. Food Control. 2016; 69: 160-170. https://doi.org/10.1016/j.foodcont.2016.04.051.

33. Ferro ID, Benetti TM, Oliveira TCRM, et al. Evaluation of antimicrobial resistance of Campylobacter isolated from broiler carcasses. Br Poult Sci. 2015; 56(1): 66-71.

https://doi.org/10.1080/00071668.2014.981796.

34. European Food Safety Authority, European Centre for Disease Prevention and Control. EU Summary Report on antimicrobial resistance in zoonotic and indicator bacteria from humans, animals and food in 2013. EFSA J. 2015; 13(2): 4036. https://doi.org/10.2903/j.efsa.2015.4036.

35. Ma L, Wang Y, Shen J, et al. Tracking Campylobactercontamination along a broiler chicken production chain from the farm level to retail in China. Int J Food Microbiol. 2014; 181: 77-84.

36. Babapour AL, Azami L, Fartashmehr J, et al. Overview of antibiotic residues in beef and mutton in Ardebil, North West of Iran. World Appl Sci J. 2012; 19(10): 1417-1422.

37. Wieczorek K, Osek J. Antimicrobial resistance mechanisms among Campylobacter. BioMed Res Int. 2013; 2013: 340605. http://dx.doi.org/10.1155/2013/340605.

38. Samad M. Public health threat caused by zoonotic diseases in Bangladesh. Bangl J Vet Med. 2011; 9(2): 95-120. https://doi.org/10.3329/bjvm.v9i2.13451.

39. European Food Safety Authority. Scientific Opinion on Campylobacterin broiler meat production: control options and performance objectives and/or targets at different stages of the food chain. EFSA J. 2011; 9(4): 2105. https://doi.org/10.2903/j.efsa.2011.2105.

40. Pissol AD, Cansian RL. The effect of water pressure and chlorine concentration on microbiological characteristics of spray washed broiler carcasses. Poult Sci J. 2013; 1(2): 63-77. https://doi.org/10.22069/PSJ.2013.1483. 
41. Svetoch E, Stern N. Bacteriocins to control Campylobacter in poultry-a review. Poult Sci. 2010; 89(8):1763-1768. https://doi.org/10.3382/ps.2010-00659.

42. Federighi M. How to control Campylobacter in poultry farms?: an overview of the main strategies. Poultry Science, 2017; 115-132. https://dx.doi.org/10.5772/64846.

\section{Tables}

Table 1 Occurrence of Campylobacter spp. along the poultry supply chain (hatchery, broiler farm and LBM) in selected poultry-dense regions in Bangladesh*.

\begin{tabular}{|c|c|c|c|c|c|c|c|c|c|c|c|}
\hline \multirow{2}{*}{$\begin{array}{l}\text { Region } \\
\text { (Sub- } \\
\text { district) }\end{array}$} & \multirow{2}{*}{$\begin{array}{l}\text { Hatchery } \\
\mathrm{CM},+/ \mathrm{N} \\
(\%)\end{array}$} & \multicolumn{5}{|c|}{ Broiler Farm, +/N (\%) } & \multicolumn{4}{|c|}{ Live Bird Market, +/N (\%) } & \multirow{2}{*}{$\begin{array}{l}\text { Total, } \\
+/ \mathrm{N}(\%)\end{array}$} \\
\hline & & F & $\mathrm{W}$ & CS & $\mathrm{BM}-\mathrm{F}$ & $\begin{array}{l}\text { Sub- } \\
\text { total }\end{array}$ & $\overline{\mathrm{W}}$ & FS & BM-M & $\begin{array}{l}\text { Sub- } \\
\text { total }\end{array}$ & \\
\hline $\begin{array}{l}\text { Gazipur } \\
\text { sadar }\end{array}$ & $0 / 15(0)$ & $0 / 9(0)$ & $5 / 12(42)$ & $\begin{array}{l}11 / 21 \\
(52)\end{array}$ & $\begin{array}{l}3 / 12 \\
(25)\end{array}$ & $\begin{array}{l}19 / 54 \\
(35)\end{array}$ & $6 / 9(67)$ & $\begin{array}{l}4 / 9 \\
(44)\end{array}$ & $\begin{array}{l}7 / 12 \\
(58)\end{array}$ & $\begin{array}{l}17 / 30 \\
(57)\end{array}$ & $\begin{array}{l}36 / 99 \\
(36)\end{array}$ \\
\hline Sreepur & $0 / 9(0)$ & $0 / 6(0)$ & 2/6 (33) & $6 / 14(43)$ & $\begin{array}{l}3 / 8 \\
(38)\end{array}$ & $\begin{array}{l}11 / 34 \\
(32)\end{array}$ & $3 / 6(50)$ & $\begin{array}{l}2 / 6 \\
(33)\end{array}$ & $5 / 9(56)$ & $\begin{array}{l}10 / 21 \\
(48)\end{array}$ & $\begin{array}{l}21 / 64 \\
(33)\end{array}$ \\
\hline $\begin{array}{l}\text { Tangail } \\
\text { sadar }\end{array}$ & $0 / 9(0)$ & $0 / 6(0)$ & $1 / 6(17)$ & $4 / 14(29)$ & $\begin{array}{l}2 / 8 \\
(25)\end{array}$ & $\begin{array}{l}7 / 34 \\
(21)\end{array}$ & 2/6 (33) & $\begin{array}{l}3 / 6 \\
(50)\end{array}$ & 2/6 (33) & $\begin{array}{l}7 / 18 \\
(39)\end{array}$ & $\begin{array}{l}14 / 61 \\
(23)\end{array}$ \\
\hline All & $0 / 33(0)$ & $0 / 21(0$ & $8 / 24$ & $\begin{array}{l}21 / 49 \\
(43)\end{array}$ & $\begin{array}{l}8 / 28 \\
(29)\end{array}$ & $\begin{array}{l}37 / 122 \\
(30)\end{array}$ & $11 / 21(52)$ & $\begin{array}{l}9 / 21 \\
(43)\end{array}$ & $\begin{array}{l}14 / 27 \\
(52)\end{array}$ & $\begin{array}{l}34 / 69 \\
(49)\end{array}$ & $\begin{array}{l}71 / 224 \\
(32)\end{array}$ \\
\hline Significant & Association & Farm v & ariables & Category & (n) & $\mathrm{p}$-value & Market vo & ariable & sCategory & $(\mathrm{n})$ & $p$-value \\
\hline Relation & & & & $\begin{array}{l}{[+/+]:[} \\
+/-]\end{array}$ & $\begin{array}{l}{[-/+]:} \\
{[-/-]}\end{array}$ & & & & $\begin{array}{l}{[+/+]:[} \\
+/-]\end{array}$ & $\begin{array}{l}{[-/+]:} \\
{[-/-]}\end{array}$ & \\
\hline \multirow[t]{6}{*}{$\begin{array}{l}\text { (Fisher's } \\
\text { exact) }\end{array}$} & & $\mathrm{W} /(\mathrm{Cs}$ & $+\mathrm{FBM})$ & {$[8]:[0]$} & $\begin{array}{l}{[7]:} \\
{[11]}\end{array}$ & 0.0074 & $\mathrm{~W} / \mathrm{MBM}$ & & [10] : [3] & [1] : [7] & 0.0075 \\
\hline & & $\mathrm{CS} / \mathrm{FE}$ & & [7] : [1] & $\begin{array}{l}{[5]:} \\
{[13]}\end{array}$ & 0.0093 & $\mathrm{FS} / \mathrm{MBN}$ & & [9] : [0] & [4] : [8] & 0.0046 \\
\hline & Difference & \multirow{2}{*}{\multicolumn{2}{|c|}{ Sub-district wise }} & \multicolumn{2}{|c|}{ Category (n) } & p-value & \multicolumn{2}{|c|}{ Source wise } & \multirow{2}{*}{\multicolumn{2}{|c|}{$\frac{\text { Category }(\mathrm{n})}{[+]:[+][-]:[-]}$}} & p-value \\
\hline & & & & {$[+]:[+$} & {$[-]$} & & & & & & \\
\hline & & $\begin{array}{l}\text { Gazipur } \\
\text { Tangail }\end{array}$ & & {$[36]:[14$} & $\begin{array}{l}{[63]} \\
{[47]}\end{array}$ & 0.082 & Farm vs. 1 & Mark & t [37]: & $\begin{array}{l}{[85]:} \\
{[35]}\end{array}$ & 0.0125 \\
\hline & & $\begin{array}{l}\text { (Farm } \\
\text { total ) }\end{array}$ & market & & & & $\begin{array}{l}\text { (Overall s } \\
\text { total) }\end{array}$ & sub- & & & \\
\hline
\end{tabular}

${ }^{*} \mathrm{CM}, \mathrm{F}, \mathrm{W}, \mathrm{CS}, \mathrm{BM}-\mathrm{F}, \mathrm{FS}$ and BM-M indicate chick meconium, feed, drinking water, cloacal swab, farm broiler meat, floor swab, and market broiler meat, respectively. Significant relations were determined by comparing data for each pair of cases under each category. 
Table 2 Multi-drug resistance patterns among the poultry-originated strains of $C$. jejuni and C. coli.

\begin{tabular}{|c|c|c|c|c|c|}
\hline \multirow{2}{*}{$\begin{array}{l}\text { Resistance } \\
\text { Category } \\
\end{array}$} & \multirow[t]{2}{*}{ Resistance patterns* } & \multicolumn{2}{|c|}{ C. jejuni $(\mathrm{n}=47)$} & \multicolumn{2}{|c|}{ C. $\operatorname{coli}(\mathrm{n}=24)$} \\
\hline & & No. of strains (\%) & Sub-total (\%) & No. of strains (\%) & Sub-total (\%) \\
\hline \multirow[t]{3}{*}{ Against two } & AMX-STR & $3(6)$ & $10(21)$ & $2(8)$ & $4(16)$ \\
\hline & AMX-TET & $5(11)$ & & $2(8)$ & \\
\hline & ER-CIP & $2(4)$ & & $0(0)$ & \\
\hline \multirow[t]{3}{*}{ Against three } & ER-STR-CIP & $5(11)$ & $11(23)$ & $3(13)$ & $6(25)$ \\
\hline & AMX-ER-NOR & $3(6)$ & & $2(8)$ & \\
\hline & AMX-TET-CIP & $3(6)$ & & $1(4)$ & \\
\hline Against four & AMX-STR-TET-CIP & $3(6)$ & $3(6)$ & $1(4)$ & $1(4)$ \\
\hline \multirow[t]{2}{*}{ Against five } & AMX-ER-TET-NOR-AZM & $3(6)$ & $5(11)$ & $2(8)$ & $3(12)$ \\
\hline & AMX-ER-TET-NOR-GEN & $2(4)$ & & $1(4)$ & \\
\hline Against six & AMX-ER-TET-CIP-NOR-AZM & $4(9)$ & $4(9)$ & $0(0)$ & $0(0)$ \\
\hline Total & & $33(70)$ & & $14(58)$ & \\
\hline
\end{tabular}

*Resistant to antimicrobials at standard doses $(\mu \mathrm{g})$ : amoxycillin (AMX, $30 \mu \mathrm{g}$ ), streptomycin (STR, $10 \mu \mathrm{g})$, erythromycin (ER, $30 \mu \mathrm{g})$, tetracycline (TET, $30 \mu \mathrm{g})$, ciprofloxacin (CIP, $5 \mu \mathrm{g}$ ), norfloxacin (NOR, $10 \mu \mathrm{g}$ ), gentamicin (GM, $10 \mu \mathrm{g}$ ), and azithromycin (AZM, $30 \mu \mathrm{g})$.

Table 3 Occurrence of antimicrobial residues in meat and liver of broiler chicken.

\begin{tabular}{|c|c|c|c|c|c|c|c|c|}
\hline \multirow{2}{*}{$\begin{array}{l}\text { Antimicrobial } \\
\text { agent }\end{array}$} & \multicolumn{4}{|c|}{ Meat samples $(n=26)$} & \multicolumn{4}{|c|}{ Liver samples $(n=24)$} \\
\hline & $\begin{array}{l}\text { Positive } \\
\text { [n (\%)] }\end{array}$ & $\begin{array}{l}\text { Median } \pm \\
\text { SD } \\
\left(\mu g \mathrm{Kg}^{-1}\right)\end{array}$ & $\begin{array}{l}\text { Range } \\
(\mu g \mathrm{Kg} \\
\left.{ }^{1}\right)\end{array}$ & $\begin{array}{l}\text { Above } \\
\text { acceptance } \\
{[\mathrm{n}(\%)]}\end{array}$ & $\begin{array}{l}\text { Positive } \\
\text { [n (\%)] }\end{array}$ & $\begin{array}{l}\text { Median } \pm \\
\text { SD } \\
\left(\mu g \mathrm{Kg}^{-1}\right)\end{array}$ & $\begin{array}{l}\text { Range } \\
(\mu g \mathrm{Kg} \\
\left.{ }^{1}\right)\end{array}$ & $\begin{array}{l}\text { Above } \\
\text { acceptance } \\
\text { [n (\%)] }\end{array}$ \\
\hline Oxytetracycline & $8(31)$ & $72 \pm 52$ & $10-140$ & $2(8)$ & $9(38)$ & $86 \pm 38$ & $\begin{array}{l}30- \\
155\end{array}$ & $4(17)$ \\
\hline Ciprofloxacin & $5(19)$ & $93 \pm 42$ & $25-130$ & $2(8)$ & $6(25)$ & $90 \pm 34$ & $\begin{array}{l}50- \\
135\end{array}$ & $3(13)$ \\
\hline Enrofloxacin & $3(12)$ & $75 \pm 29$ & $55-115$ & $1(4)$ & $4(17)$ & $81 \pm 23$ & $\begin{array}{l}50- \\
105\end{array}$ & $1(4)$ \\
\hline Total & $16(62)$ & $76 \pm 43$ & $10-140$ & $5(19)$ & 19 (79) & $87 \pm 33$ & $\begin{array}{c}30- \\
155\end{array}$ & $8(33)$ \\
\hline
\end{tabular}




\section{Figures}
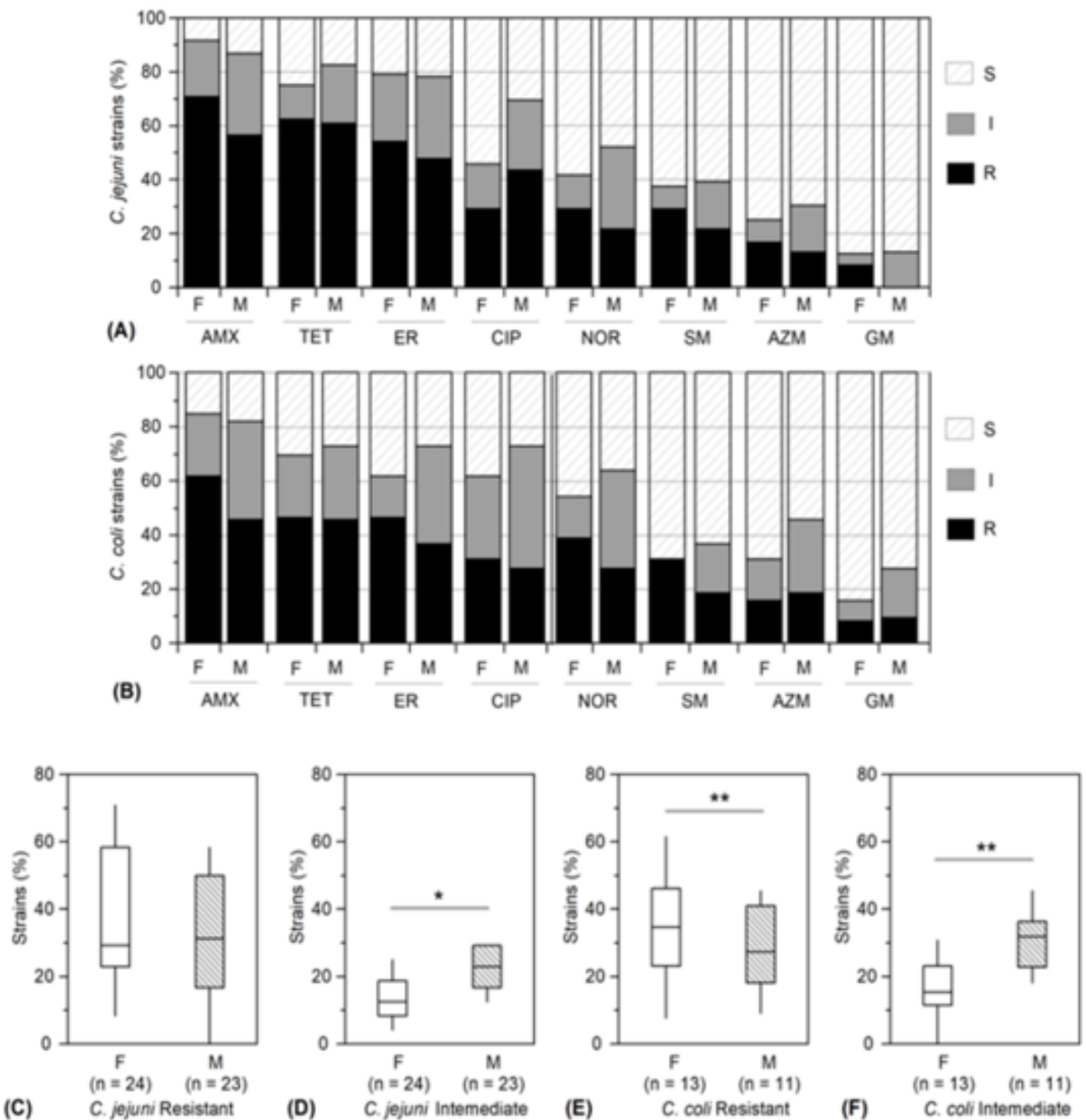

\section{Figure 1}

Comparative occurrence of resistant C. jejuni and C. coli strains isolated from broiler farms (F) and retail markets $(\mathrm{M})$. Eight commonly used antimicrobials at standard doses $(\mu \mathrm{g})$ were examined: amoxycillin (AMX, $30 \mu \mathrm{g})$, tetracycline (TET, $30 \mu \mathrm{g})$, erythromycin (ER, $30 \mu \mathrm{g})$, ciprofloxacin (CIP, $5 \mu \mathrm{g})$, norfloxacin (NOR, $10 \mu \mathrm{g})$, streptomycin (STR, $10 \mu \mathrm{g})$, azithromycin (AZM, $30 \mu \mathrm{g})$, and gentamicin (GM, $10 \mu \mathrm{g})$. The bottom and top of the box plots indicate the 25th and 75th percentile. Horizontal lines in the boxes indicate median values and their standard deviations are shown as vertical bars. ${ }^{*} p<0.05$ and ${ }^{\star *} p<0.01$, significant differences (paired t test) between mean values of the samples. 
(R15) Antimicrobial use for treatment \& growth

(R14) Fecal waste disposal to agri-land

(R13) Basic training on farm mangement (R12) Human gastroenteritis (R11) Interrupted sunlight availability (R10) Pre-handling handwashing (R9) Isolation of sick chicken (R8) Periodic health check (R7) Campylobacteriosis symptom (R6) Use of cleaning solution (R5) Fecal disposal to pond (R4) Post-handling hand washing (R3) Regular handwashing before eating

(R2) Regular cleaning of feeder/waterer (R1) Weekly floor cleaning

(A)

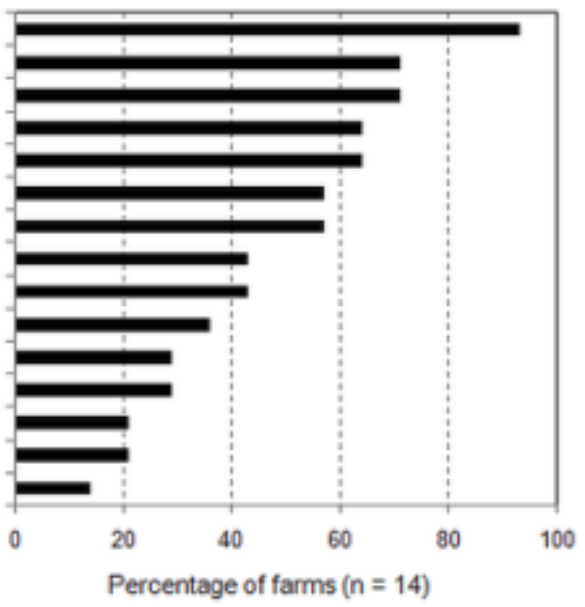

\begin{tabular}{l}
\hline Risk categories (R) \\
\cline { 2 - 4 } (R7) Campylobacteriosis symptom in broilers \\
(R15) Antimicrobial use for treatment \& growth \\
(R12) Human gastroenteritis \\
(R3) Irregular handwashing before eating \\
(R1) Lapse of weekly floor cleaning \\
(R2) Irregular cleaning of feeder/waterer \\
(R6) No use of cleaning solution \\
(R8) Lack of periodic health check of broilers \\
(R4) Infrequent post-handling hand washing \\
(R11) Interrupted sunlight \\
(R14) Fecal waste disposal to agri-land \\
(R9) No isolation of sick chicken \\
(R5) Fecal disposal to pond \\
(R10) Infrequent pre-handling handwashing F12 F13 \\
(R13) No basic training on farm mangement \\
(B)
\end{tabular}

(B)

ares $\square=$ No

\section{Figure 2}

Anthropogenic factors associated with the occurrence of MDR strains of Campylobacter in the broiler farms. (A) Overall prevalence of the probable risk factors in the selected farms. (B) Individual farm-wise categorization of the risk factors in relation to symptomatic and asymptomatic infections of Campylobacter. Data were obtained at two phases (3-month interval) by interviewing (semi-structured questionnaires) 56 representatives of 14 farms, including 9 (F1-F9) sites examined for contamination of MDR Campylobacter.

\section{Supplementary Files}

This is a list of supplementary files associated with this preprint. Click to download.

- SupplementalMaterials.pdf 